\title{
COMMUNICABLE DISEASES, NSW: MARCH 2001
}

\section{TRENDS}

Notifications of communicable diseases in January 2001 were mainly in line with seasonal expectations (Figure 9, Table 3). Case reports of the arboviruses, Ross River virus and Barmah Forest infections, rose with the onset of summer, but have yet to reach the heights of previous seasons. Case reports of pertussis continue to decline, and monthly notifications of hepatitis A have remained relatively low for two years. This month we have included a graph of new HIV diagnoses reported by reference laboratories in NSW. The fall-off in notifications of HIV in recent months most likely reflects reporting delays. Despite monthto-month fluctuations, these data suggest a fairly consistent rate of new HIV infections in NSW over time.

\section{MURRAY VALLEY ENCEPHALITIS VIRUS ACTIVITY IN WESTERN NSW}

Murray Valley Encephalitis (MVE) is a potentially serious infection caused by a flavivirus that is transmitted by mosquitoes. Only one in approximately 1,000 persons infected will develop symptoms that include headache, neck stiffness, fever, tremor, weakness, confusion, fitting, and sometimes coma and death. It occurs at low level endemicity in north-western Australia, and is rare in NSW. The last occurrence in NSW was in 1974, as part of a nation-wide outbreak that led to approximately 58 cases, five of whom were infected in NSW. Thirteen people died. ${ }^{1}$

Following the 1974 outbreak, an early-warning system for detecting the presence of flaviviruses was developed. Sentinel flocks of chickens are placed at various locations in inland NSW. The chickens' blood samples are tested weekly for antibodies to flaviviruses, including MVE and Kunjin. Mosquitos are also trapped for identification, quantification and virus isolation. Until February 2001, MVE had never been identified in the NSW chickens, or isolated from mosquitoes, since the program began 12 years ago. MVE has not been identified in people in NSWwith encephalitis since 1974.

On the 15th February, testing (at the Institute of Clinical Pathology and Medical Research, Westmead Hospital, and also at the University of Western Australia) confirmed that MVE virus had been detected in the sentinel chicken flocks in remote western NSW: in two chickens from Menindee, two from Macquarie Marshes and one from Wanaaring. Other chickens in the affected flocks also seroconverted to Kunjin virus. On 21 February, further testing of the chickens indicated ongoing flavivirus activity in the Macquarie Marshes, and also detected activity at Bourke (also in western NSW).

In response, the public health units in the affected areas provided advice to local hospitals to report suspected human infection. No human clinical cases of MVE or
Kunjin virus infection have been identified to date (late February). The NSW Department of Health provided a media warning that MVE is likely to be present in NSW and that people in those areas should take personal protection measures to avoid being bitten by mosquitoes. Surveillance continues.

\section{REFERENCE}

1. Forbes JA. Murray Valley encephalitis 1974 and The epidemic variance since 1914 and predisposing rainfall patterns. Sydney: Australasian Medical Publishing, 1978.

\section{NSW PUBLIC HEALTH BULLETIN}

The NSW Public Health Bulletin is a publication of the NSW Department of Health.

The editor is Dr Lynne Madden, Manager, Public Health Training and Development Unit.

Dr Michael Giffin is managing editor.

The Bulletin aims to provide its readers with population health data and information to support effective public health action.

\section{Submission of articles}

Articles, news and comments should be 1000 words or less in length and include a summary of the key points to be made in the first paragraph. References should be set out in the Vancouver style, described in the New England Journal of Medicine, 1997; 336: 309-315. Send submitted articles on paper and in electronic form, either on disc (Word for Windows is preferred), or by email. The article must be accompanied by a letter signed by all authors. Full instructions for authors are available on request from the managing editor.

\section{Editorial correspondence}

Please address all correspondence and potential contributions to The Editor, NSW Public Health Bulletin, Locked Mail Bag 961, North Sydney, NSW 2059, Australia or by email to phbulletin@doh.health.nsw.gov.au.

Tel: 6129391 9241, Fax: 61293919232.

\section{Distribution}

Please contact your local Public Health Unit or telephone 62293919942 to obtain copies of the NSW Public Health Bulletin. A new subscribers/ change of address form is printed in most issues of the Bulletin for your use. The Bulletin can be accessed via the Internet from the Department's Web site at: www.health.nsw.gov.au/public-health/phb/ phb.html. Back issues can be obtained from the Public Health Training and Development Unit, Locked Mail Bag 961, North Sydney, NSW 2059, Australia.

Copyright $(2001$ NSW Department of Health

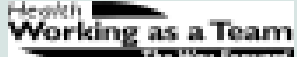




\section{FIGURE 9}

\section{REPORTS OF SELECTED COMMUNICABLE DISEASES, NSW, JANUARY 1996 TO JANUARY 2001, BY MONTH OF ONSET}

These are preliminary data: case counts for recent months may increase because of reporting delays. Laboratory-confirmed cases, except for measles, meningococcal disease and pertussis _ actual __ predicted after adjusting for likely reporting delays

\begin{tabular}{|rr|}
\hline \multicolumn{2}{|c|}{ NSW population } \\
Male & $50 \%$ \\
$<5$ & $7 \%$ \\
$5-24$ & $28 \%$ \\
$25-64$ & $52 \%$ \\
$65+$ & $13 \%$ \\
Rural* $^{*}$ & $42 \%$ \\
\hline
\end{tabular}

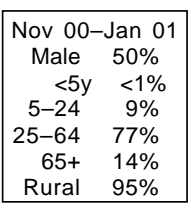

cases

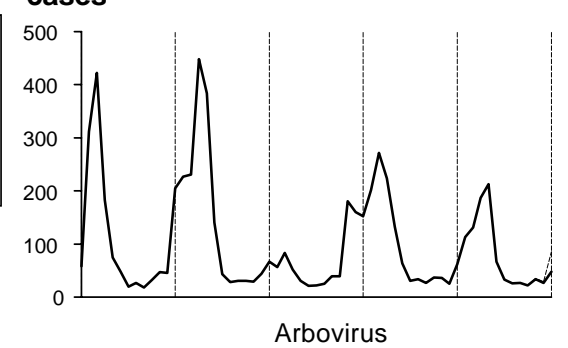

\begin{tabular}{|rc|}
\hline \multicolumn{2}{|c|}{ Nov 00-Jan 01 } \\
Male & $52 \%$ \\
$<5$ & $63 \%$ \\
$5-24$ & $35 \%$ \\
$25-64$ & $2 \%$ \\
$65+$ & $0 \%$ \\
Rural & $89 \%$ \\
\hline
\end{tabular}
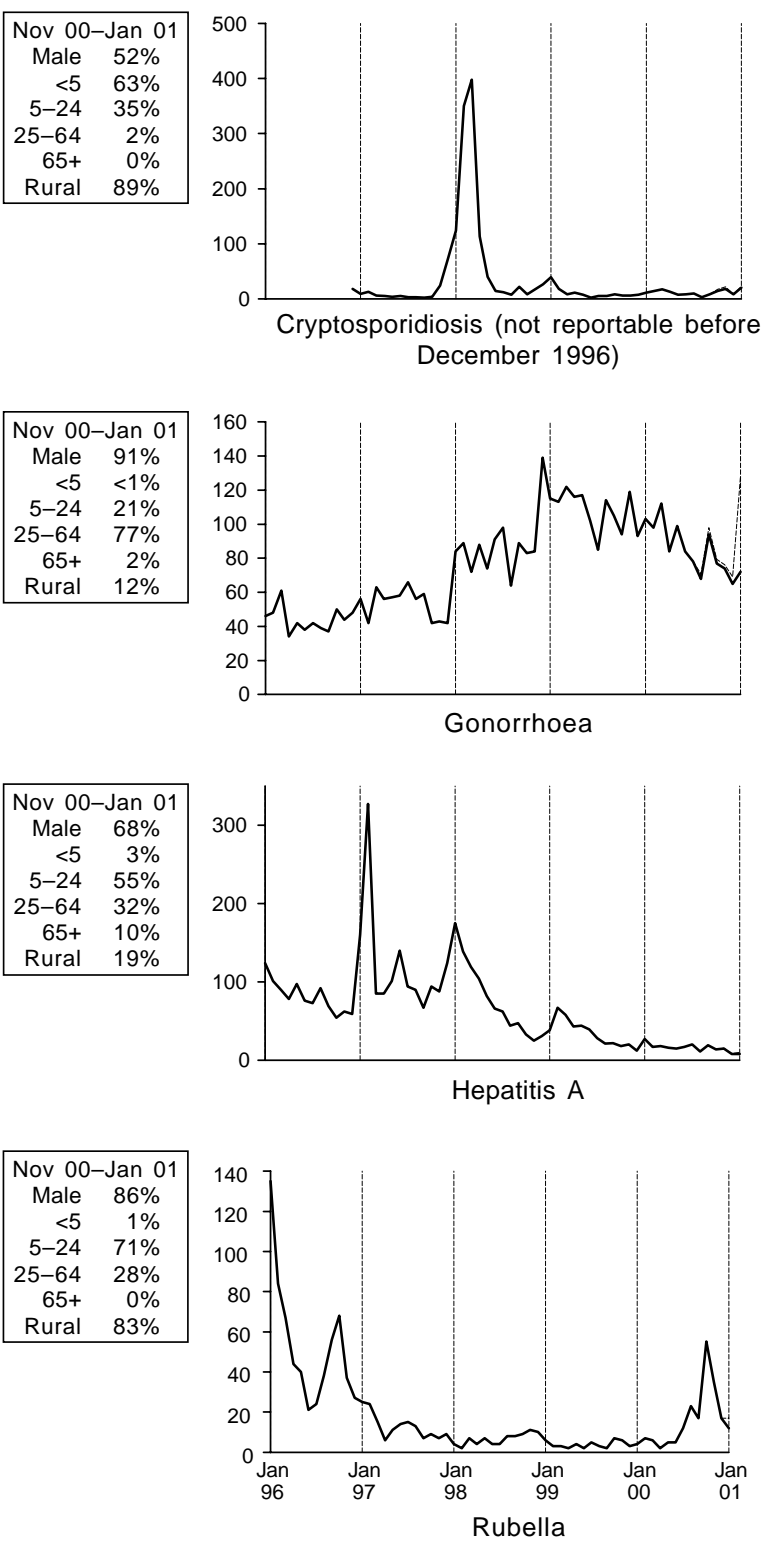

cases

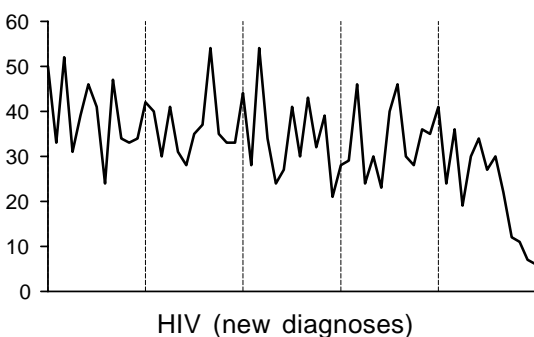

Nov 00-Jan 01 Male $87 \%$ $\begin{array}{rr}<5 \\ 5-24 & 22 \%\end{array}$ $25-64 \quad 61 \%$ $65+9 \%$ Rural $17 \%$ HIV (new diagnoses)

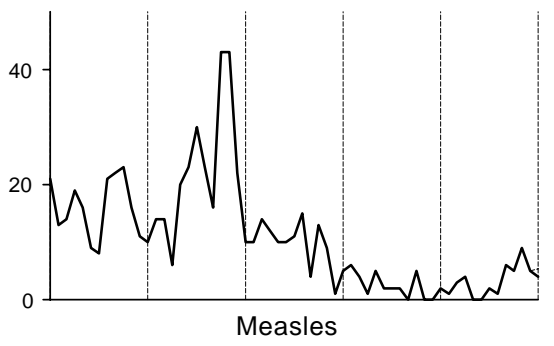

Nov 00-Jan 01 Male $67 \%$

$<5 \quad 50 \%$ 5-24 44\% $65+\quad 0 \%$ Rural $6 \%$
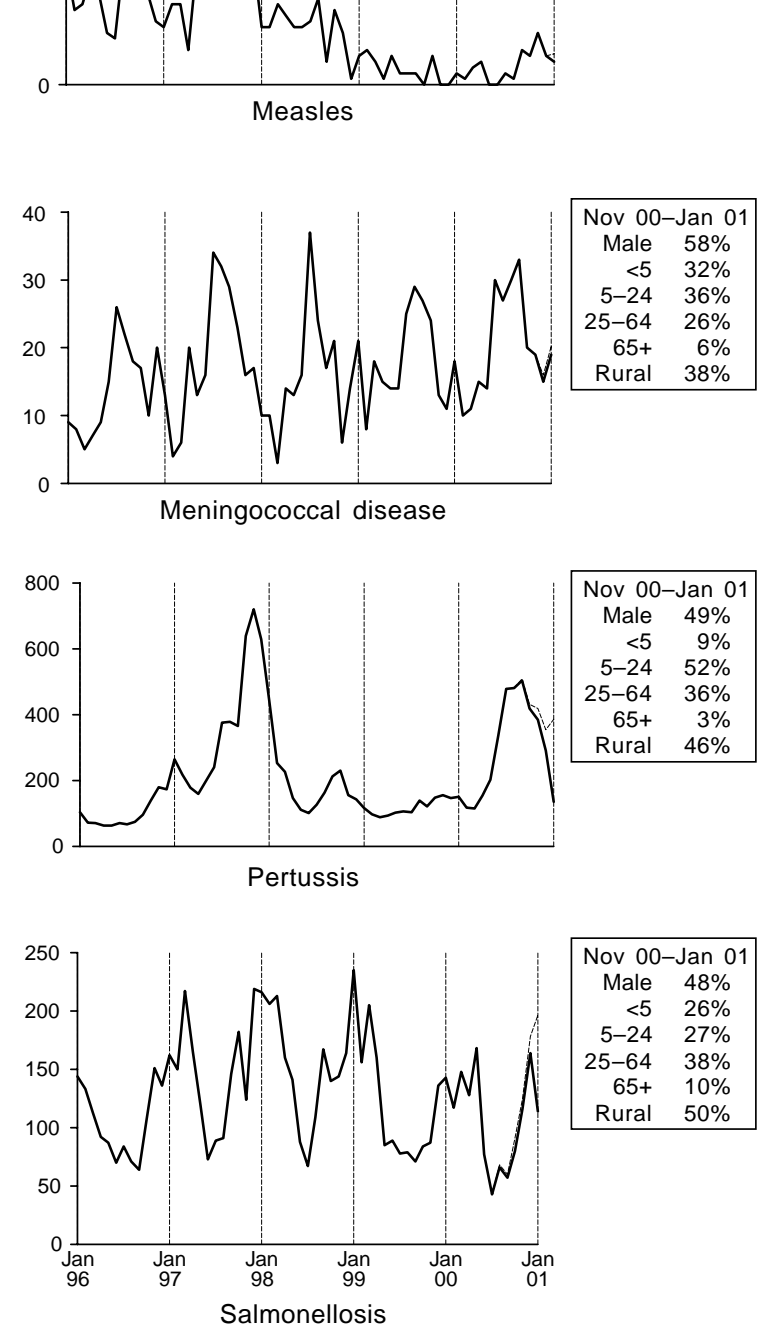

* For definition, see NSW Public Health Bulletin, April 2000 


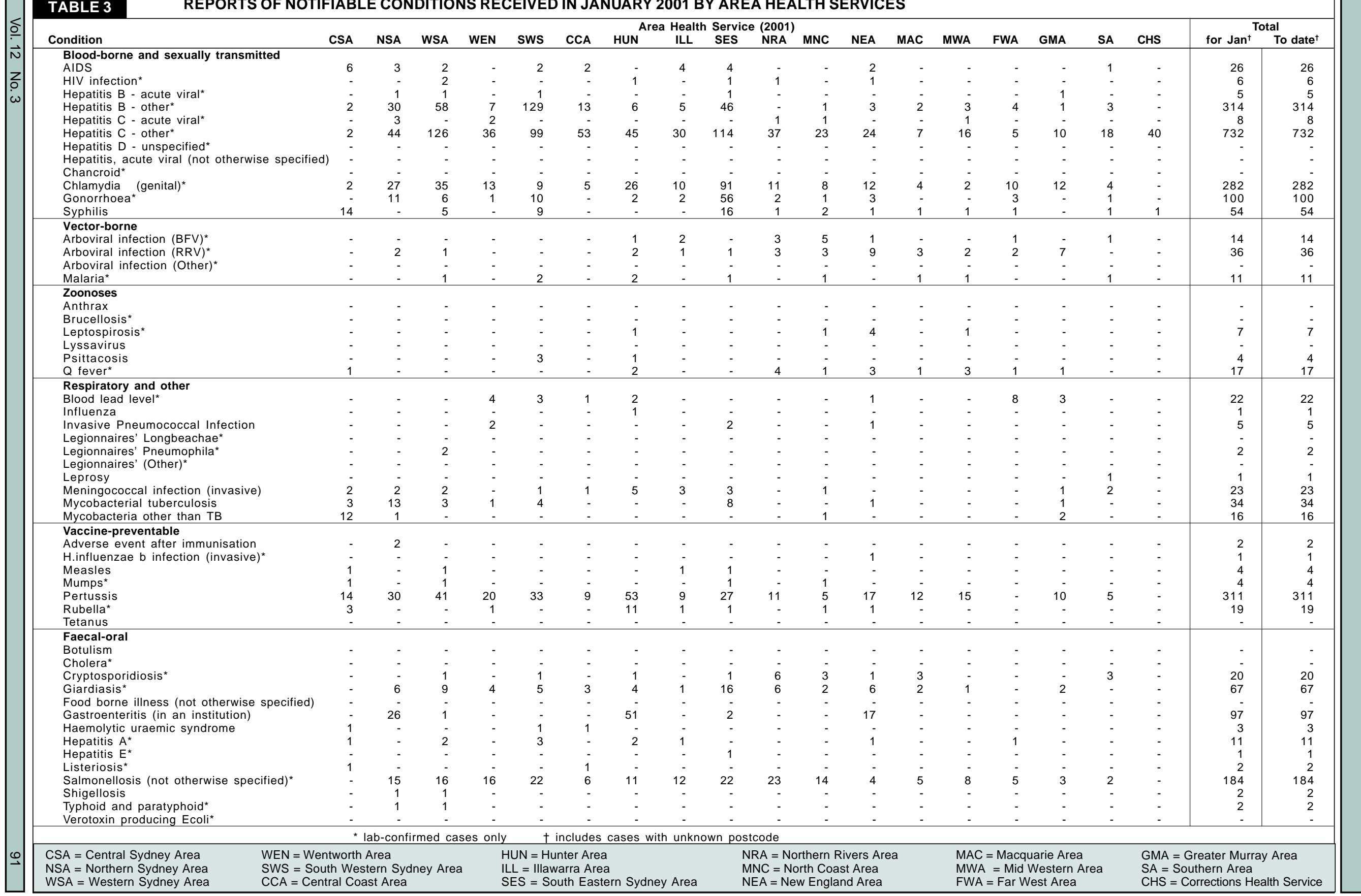

